\section{Commentary: Pursuing the Pareto frontier in education}

\author{
David L. Joyce, MD, MBA
}

Italian engineer and economist Vilfredo Pareto famously described a set of conditions in a negotiation in which a given party could only be made better off by making the other party worse off. The entire set of combinations where this theory holds has been described as the Pareto frontier, and failure to achieve Pareto efficiency in this way suggests that money is being left on the table. As surgical educators, we often find ourselves in pursuit of the Pareto frontier as we balance the desire to optimize trainee experience against operational efficiency and patient safety. In their outstanding review of the cardiothoracic educational literature between 2018 and 2019, Hunt and colleagues ${ }^{1}$ have given us a number of innovative strategies to strike this balance in a way that maximizes payoffs for all parties.

Sobering although sadly not surprising are the data presented here that $81 \%$ of female and $46 \%$ of male trainees experienced some form of harassment during their training. ${ }^{2}$ In our efforts to motivate and inspire the next generation of leaders to join our ranks, we must first address the cultural opportunity we have to promote diversity and inclusion. Burnout is not just leaving money on the table, it's lighting $\$ 100$ bills on fire.

Another intriguing concept brought forward in this manuscript is the argument for better data when it comes to evaluating resident performance. The authors correctly point out that the Accreditation Council for Graduate Medical Education trends with respect to first assistant and teaching assistant roles should be viewed with a healthy degree of skepticism. According to Stanford cardiac surgical lore, Thelma and Henry Doegler Professor Emeritus

\footnotetext{
From the Department of Surgery, Froedtert \& Medical College of Wisconsin, Milwaukee, Wis.

Disclosures: The author reported no conflicts of interest.

The Journal policy requires editors and reviewers to disclose conflicts of interest and to decline handling or reviewing manuscripts for which they may have a conflict of interest. The editors and reviewers of this article have no conflicts of interest.

Received for publication April 7, 2020; revisions received April 7, 2020; accepted for publication April 8, 2020; available ahead of print April 18, 2020.

Address for reprints: David L. Joyce, MD, MBA, Division of Cardiothoracic Surgery, Department of Surgery, Froedtert \& Medical College of Wisconsin, 9200 W Wisconsin Ave, Milwaukee, WI 53226 (E-mail: djoyce@mcw.edu).

J Thorac Cardiovasc Surg 2020;160:1139

$0022-5223 / \$ 36.00$

Copyright (c) 2020 by The American Association for Thoracic Surgery

https://doi.org/10.1016/j.jtcvs.2020.04.036
}

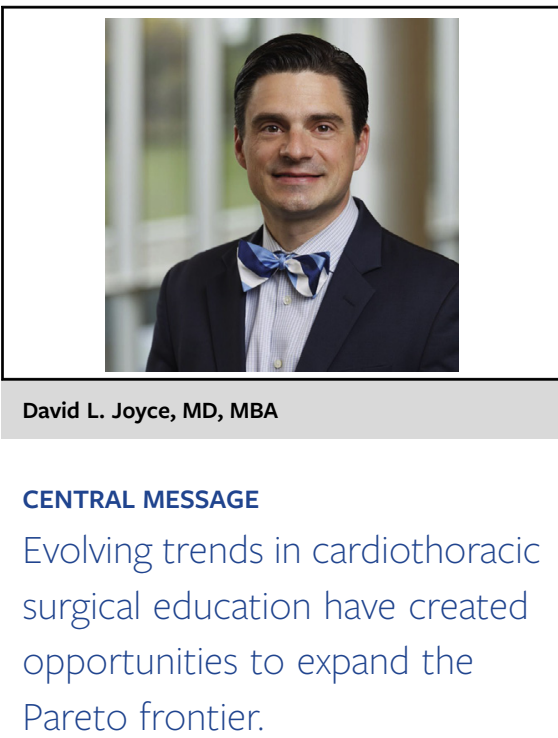

Edward Stinson once broke down an open-heart operation into more than 100 clearly defined individual steps. It is absurd to suggest that each of the residents logging a coronary artery bypass grafting procedure as primary surgeon has been given an identical operative experience. Our group, along with a consortium of partners who currently use the System for Improving and Measuring Procedural Learning app, ${ }^{3}$ has proposed moving toward case component logging as a better metric for providing feedback to trainees and educators alike.

Beyond pursuit of the Pareto frontier, simulation continues to hold the promise of expanding the options available to create educational value with fewer tradeoffs. Trainees who enter the operating room with skills developed through the types of high-fidelity models described in this article will be much better prepared to claim a larger piece of the educational pie that is available in every operative procedure.

\section{References}

1. Hunt MF, Giuliano K, Etchill E, Yang SC. Cardiothoracic surgery educational research and training innovation: a review of 2018-2019. J Thorac Cardiovasc Surg. 2020;160:1133-7.

2. Ceppa DP, Dolejs SC, Boden N, Phelan S, Yost KJ, Donington J, et al. Sexual harassment and cardiothoracic surgery: \#UsToo? Ann Thorac Surg. 2020;109: 1283-8.

3. George BC, Bohnen JD, Schuller MC, Fryer JP. Using smartphones for trainee performance assessment: a SIMPL case study. Surgery. October 23, 2019 [Epub ahead of print]. 